\title{
Geografia de Gênero e Trabalho Familiar: Algumas Considerações
}

\author{
Geography of Gender and Family Work: Some Considerations
}

\author{
Maria Luíza Oliveira de Francisco \\ Faculdades Adamantinenses Integradas \\ fran@spdnet.com.br
}

\section{Resumo}

Este trabalho examina a Geografia de Gênero e suas relações com o trabalho familiar, procurando destacar as atividades reprodutivas e produtivas desenvolvidas pela mulher, conjuntamente com os outros membros da família nas estratégias de sobrevivência familiar. Primeiramente, aborda as origens da Geografia de Gênero em termos de contribuições das correntes de pensamento geográfico. Depois, trata da relação entre Geografia de Gênero e Meio Rural. Finalmente, identifica e caracteriza as relações entre Geografia de Gênero e Trabalho Familiar ressaltando as ligações entre o trabalho feminino $\mathrm{e}$ as estratégias de sobrevivência familiar.

Palavras-chave: Geografia, Geografia de Gênero, Meio Rural, Estratégias de Sobrevivência Familiar.

\begin{abstract}
This work examines the Geography of Gender and its relationships with family work, trying to focus the reproductive and productive activities developed by women along with other family members in strategies for family survival. First, it approaches the origins of the Geography of Gender in terms of contributions of Geographic Thought trends. Then, it is about the relationship between Geography of Gender and Rural Environment. Finally, it identifies and describes the relationships between Geography of Gender and Family Work highlighting the connections between feminine work and family survival strategies.
\end{abstract}

Keywords: Geography; Geography of Gender; Rural Environment; Family Work; Strategies for Family Survival. 


\section{Introdução}

A instalação e o desenvolvimento da Geografia de Gênero, na década de setenta, representou um significativo avanço para a Geografia Humana. Muito embora, hoje, se tenha uma diversidade de temas e enfoques sobre a mulher na Geografia, no início, os estudos se caracterizaram pela busca de uma identidade própria que exigiu o estabelecimento de bases conceituais e metodológicas precisas para $\mathrm{o}$ desenvolvimento das pesquisas. Assim, os estudos de gênero iniciados no final da década de setenta, originários dos Estados Unidos da América do Norte, Canadá, Grã-Bretanha, França, Itália e Holanda constituem uma expressão acadêmica do movimento das mulheres.

Estes estudos, que demonstravam suas origens políticas, identificavam questões da desigualdade do status da mulher na sociedade e na disciplina. $\mathrm{Na}$ realidade, estes trabalhos buscavam 'fazer visível' a mulher, seus papéis, seus trabalhos, suas experiências, ou seja, documentá-la em toda sua diversidade. Neste contexto, Monk e Ramon (1987) ressaltam que duas temáticas caracterizaram os primeiros estudos feministas na Geografia, ou seja, a crítica da Geografia que dava por suposto que a experiência masculina equivalia à experiência humana e a descrição empírica da Geografia das mulheres para demonstrar como ela era distinta da dos homens.

Portanto, o estabelecimento dos fundamentos teóricos e metodológicos se dá através do desenvolvimento dos trabalhos feministas, realizados por Geógrafas e Geógrafos de diversas partes do mundo. Embora, esta efetivação ainda esteja ocorrendo no momento atual, pois novos estudos surgem constantemente, buscando avançar teórica e metodologicamente no campo da disciplina, algumas críticas têm sido levantadas em relação a este progresso. Neste sentido, Seager e Olson (1986, p.8) afirmam que "durante os últimos dez anos se tem conhecido, muito mais, sobre a vida e as experiências das mulheres em todas as partes do mundo". Isto denota uma das principais características dos primeiros estudos geográficos sobre mulher que foi seu caráter essencialmente descritivo. Estes abordavam temas como trabalho doméstico, família e distribuição do emprego feminino entre outros.

Antes, e de forma incisiva, Fortuyn salienta que: "este primeiro passo da Geografia Feminista segue sendo um elemento essencial de investigação: sempre se requer uma coleção e descrição de muitos dados elementares" (FORTUYN, 1984, p.33). Para Karsten e Meertens, a fase pioneira constituiu-se na busca de uma identidade própria onde os preceitos metodológicos foram efetivados. Mas,

Estes têm sido úteis e necessários para o arranque de uma nova disciplina, mas uma vez superada essa etapa, o que até então havia sido fonte de inspiração, agora se tem convertido em camisa de força. E a nova inspiração que se há de ter se encontra de preferência no diálogo sobre os diferentes enfoques com os quais o tema de gênero pode ser abordado na investigação geográfica. (KARSTEN; MEERTENS, 1991/1992, p.183).

Portanto, um dos caminhos apontados hoje para os estudos de Gênero na Geografia está na "relação de gênero aplicada à análise da estrutura social e espacial das sociedades" (CALIÓ, 1991, p.14). Do mesmo modo, Monk e Hanson afirmam anteriormente que,

$\mathrm{Na}$ busca de um marco teórico para compreender as desigualdades entre homens e mulheres, a geografia feminista se tem centrado em explicações que tomam em consideração os fundamentos ideológicos das distinções de gênero nas sociedades patriarcais e as bases econômicas que se inter-relacionam com elas, e tem identificado o capitalismo como uma causa fundamental das desigualdades padecidas pelas mulheres (MONK; HANSON, 1989, p.35).

Assim, a Geografia Feminista após a sua instalação, tem se desenvolvido significativamente, incorporando conceitualmente e metodologicamente à análise de gênero aos processos espaciais.

Desta forma, este trabalho procurou examinar as relações entre Geografia de Gênero e trabalho familiar destacando as atividades reprodutivas e produtivas desenvolvidas pela mulher conjuntamente com os outros membros da família nas estratégias de sobrevivência familiar.

\section{Geografia de Gênero}

A Geografia de Gênero se apresenta mais enraizada no feminismo, isto é, na perspectiva de gênero, tratando de papéis aprendidos socialmente. Assim, se constitui hoje, na principal linha de estudo na Geografia entre mulher e espaço.

Desta forma, a origem da Geografia de Gênero está relacionada a diferentes correntes do pensamento geográfico, mais especificamente, a Geografia 
Neopositivista, Geografia Humanística e Geografia Marxista. Ou como destaca as Geógrafas do Instituto Britânico de Geografia do Women and Geography Study Group - Grupo de Estudo Geografia e Mulher (WGSG) de 1984:

Assim, a Geografia Feminista havia sido precedida por e, em muitos sentidos, tivera as bases preparadas para ela, por diferentes comentários de métodos de pensamentos estabelecidos. Tanto os comentários radicais/ marxistas quanto os humanistas abriram um campo fértil para a análise feminista. Porém, o que a análise feminista tem feito não é meramente acrescentar uma outra dimensão. Em um sentido muito importante, ela tem sido instrumental tanto em levar os dois comentários adiante em novas direções. (WOMEN AND GEOGRAPHY STUDY GROUP, 1984, p. 11).

Este fato tem possibilitado à utilização de vários paradigmas até os dias atuais. Deste modo, a Geografia Humanística, no estudo da mulher, surgiu assim como as demais, na década de setenta nos Estados Unidos da América do Norte. Dessa maneira, esta corrente de estudo retrata a 'experiência vivida' das mulheres em seu espaço, ou melhor, 'as experiências das mulheres nos âmbitos físico e social', mas não analisa as relações sociais existentes. Estes trabalhos apontam como tendência geral, uma maior 'sensibilidade e percepção das mulheres' em relação aos homens. (LARIMORE, 1978; LIBBEE, 1978). Dessa forma, sob este enfoque, destacam-se os trabalhos de Buchanan (1970), Burton (1976) e Buttimer (1976). Na década de oitenta, o avanço das abordagens ambientais relacionadas ao desenvolvimento econômico proporcionou a difusão desta linha de estudo para o meio ambiente onde tem buscado 'uma relação íntima entre mulher e natureza'. Assim, originária do 'feminismo romântico' do século XIX, tendência conhecida, hoje, como 'feminismo da diferença', ressalta a existência de uma ação positiva da mulher para com o meio ambiente, ou seja, pela sua maior sensibilidade e percepção, a mulher "compreende e assume a defesa daquilo que é natural" (BISTUER, 1993, p.119). Como exemplo dessa temática, tem-se as obras de Dankelman e Davidson (1988) e Sontheimer (1991).

Esses estudos efetivaram a linha de estudo para o meio ambiente denominada de 'Ecofeminismo'. Esta foi fundamentada nas propostas de Mies (1990) e Shiva (1991), estando baseada em uma definição da identidade feminina enraizada na natureza, enquanto sob papéis reprodutivo e de fornecedora. Nessa perspectiva, a proximidade da mulher da natureza é muito mais íntima que a do homem. Essa linha de estudo tem sido criticada pela Geografia de Gênero que salienta a falta das relações sociais nos estudos desenvolvidos e a efetivação de uma atitude passiva das mulheres perante a destruição do meio ambiente. $\mathrm{Na}$ realidade, a crítica se deve ao fato do Ecofeminismo não ver a questão ambiental como um processo social, fato que ocorre com a Geografia de Gênero.

Já a Geografia Neopositivista, procurou estudar a constatação da desigualdade das mulheres no acesso aos serviços sociais, tendo por fundamento, o ajustamento dos horários pessoais com o de trabalho. Completamente desvinculada de um aprofundamento das questões sociais, ou seja, não considerando conceitos como família ou gênero, propunha a criação de modelos matemáticos para avaliar o 'tempo pessoal' e o 'tempo de trabalho' das mulheres, buscando uma melhor combinação de horários. Para tanto, baseava-se no 'modelo geográfico-temporal da sociedade de $\mathrm{T}$. Hägerstrand' que envolvia a estruturação das atividades humanas no tempo e no espaço. Ou seja:

Hägerstrand entende que o problema de planificação básico do futuro é o de determinar como as formas de povoamento e as atividades de qualquer região urbana deveriam estruturar-se no tempo e no espaço para garantir uma existência cotidiana "vivencial" a cada pessoa. Há restrições de tempo ao movimento humano e, toda atividade humana econômica e não econômica consome às vezes tempo e espaço. De modo que, a questão básica que se estabelece é a de como as atividades humanas deveriam organizar-se no tempo e no espaço para oferecer equitativo acesso a empregos, atividades de tempo livre e serviços do setor privado e do setor público (PALM e PRED, 1974; 1985, p.109).

Assim, como principal estudo e marco inicial, temse o trabalho de Palm e Pred (1974, 1985) que examinaram as implicações que as demandas de funções que se fazem as várias categorias de mulheres têm sobre sua liberdade para participar nas atividades profissionais ou de tempo livre de sua escolha. Utilizando-se do 'modelo de Hägerstrand', analisaram as restrições geográfico-temporais, especificadas como de capacidade, de autoridade e de ligação (como localização da residência, localização do emprego, localização da escola ou creche, transporte disponível 
e seus horários, horário do emprego e da escola ou creche) e as opções de atividade das mulheres que trabalham. Consideraram como problemas mais graves em relação às mulheres, a combinação de seus horários de trabalho com os das creches, das escolas e outros serviços públicos e o acesso aos meios de transporte que possibilitem a estas, desfrutar de oportunidades de emprego ou de tempo livre.

Por último, a Geografia Marxista analisa a mulher no trabalho, explorando sua posição social e econômica dentro da sociedade capitalista. Já Ramon, considera que esta Geografia "se tem preocupado primordialmente pela esfera da produção em detrimento da reprodução, que é onde a mulher em geral tem desempenhado um papel mais importante" (RAMON 1985, p.137). Sem dúvida, esta linha de estudo busca o entendimento dos processos sociais e econômicos que envolvem a posição das mulheres, ou melhor, sua subordinação dentro da sociedade capitalista. Portanto, para a Geografia Marxista, "as relações de gênero se incluem no marco mais amplo das relações sociais e se tende a explicar a subordinação da mulher sobre uma base materialista a de sua capacidade reprodutora, que não pode compreender-se desengajada dos processos de produção e reprodução social" (MCDOWELL, 1986, p.315).

Desde seu início, a Geografia Marxista, no campo da Geografia, tem voltado seus estudos para enfoques como, o próprio processo de produção com abordagens alternativas à teoria de localização econômica e, com a produção e consumo de serviços publicamente proporcionados como habitação e educação. Neste sentido, pouca atenção foi dada pelos geógrafos, desta linha de pensamento, à Geografia Feminista, ou melhor, pouca contribuição e posicionamento fora das Universidades, exceção feita a algumas geógrafas feministas, como as do Instituto Britânico de Geografia, do Grupo de Estudo Geografia e Mulher. Portanto, as contribuições para a Geografia Feminista vieram de duas áreas da Geografia Marxista, no caso, Materialismo e Estado (WGSG, 1984, p.33).

$\mathrm{Na}$ verdade, esta primeira área,

representa de fato uma combinação de materialismo e da noção de que os modos de vida são específicos de um tempo e lugar, em particular. $\mathrm{O}$ materialismo, refere-se à noção de que é impossível compreender, ou mudar a sociedade, a menos que analisemos os modos sociais e técnicos na organização que estão envolvidos, na provisão das necessidades humanas (como alimento ou abrigo), assegurando a reprodução biológica das espécies, e proporcionando o 'padrão de vida' geralmente aceito e que predomina nessa sociedade (WGSG, 1984, p. 33).

Nestes termos, a forma pela qual as pessoas sustentam um determinado padrão de vida nas sociedades capitalistas depende determinantemente do relacionamento entre capitalistas e operários. Entretanto,

o grau de controle que as mulheres podem exercer sobre sua sexualidade e sobre seus próprios corpos, bem como sobre as oportunidades de ganhar a vida, é também materialmente limitada pelas relações patriarcais. Contudo, os relacionamentos capitalista-operário e homem-mulher não são os mesmos se quer dentro da mesma economia capitalista (...), e podem diferir consideravelmente de um país capitalista para outro (WGSG, 1984, p.33).

Já a outra área, que envolve o estudo do Estado, tem sido abordada através de várias concepções que vão desde aquela de um 'aparelho', que é um instrumento voltado a atender

os interesses do grupo econômico dominante na sociedade, como, por exemplo, a classe capitalista nas sociedades capitalistas - até aquela de uma instituição essencialmente neutra que abrange e reage aos vários conflitos de preços e grupos de pressão na sociedade. Em uma ponta do espectro, a concepção instrumental do Estado implica que para ocorrer a mudança radical, a destruição completa, ou, no mínimo, a tomada de poder do aparelho do Estado por uma classe diferente (no marxismo clássico, os trabalhadores ou proletariado) tem que ser alcançada. $\mathrm{Na}$ outra extremidade do espectro, a visão de que o Estado é relativamente neutro e autônomo implica que mudanças podem ser alcançadas dentro da atual estrutura do Estado (WGSG, 1984, p.34).

Neste contexto, as feministas, principalmente as socialistas (são as que fundamentam seu estudo da opressão da mulher na análise de classes sociais e das relações de produção), enxergam uma ligação entre a luta de classe, onde os trabalhadores lutam contra a perda de seus padrões de vidas impostos diretamente pelos capitalistas, ou de forma indireta, pelo Estado e a 
luta pela liberação feminina. Mas, sua participação nessas lutas está atrelada ao fato de suas exigências serem reconhecidas.

\begin{abstract}
A menos que esta condição seja satisfeita, a subordinação das mulheres simplesmente torna-se um outro aspecto da luta de classe, e a ela é reduzida. O importante papel desempenhado pelos homens na subordinação das mulheres conforme expressado no conceito de patriarcado é diluído e perdido (WGSG, 1984, p.34).
\end{abstract}

Dessa forma, Pat Burnett foi a pioneira nesta linha de pesquisa, ou seja, foi a primeira a tratar do desenvolvimento de categorias e teorias marxistas para explicar a subordinação da mulher, em artigo publicado na revista Antípode em 1973. (BOWLBY et al., 1989, p.161). Assim, neste trabalho atacou as proposições do "empirismo lógico", enfatizando que a "teoria marxista" levava a um adequado ponto de partida para a análise das mudanças sociais e seus impactos sobre o sistema espacial urbano. (BURNETT, 1973, p.58). Ainda, salienta a necessidade de uma expansão do enfoque marxista através da introdução "das relações de poder socialmente designadas", definindo-as em termos da "psicologia masculina do poder" e, ressaltando que "talvez não seja uma generalização abusiva a considerar a totalidade do sistema espacial urbano em termo de comportamentos gerados por esta psicologia". (BURNETT, 1973, p. 60).

$\mathrm{Na}$ realidade, Burnett através de seu artigo, introduz as bases conceituais da corrente do feminismo radical centrada no "patriarcado e capitalismo" na Geografia Feminista, mais precisamente, no espaço urbano.

Outros trabalhos, como os de Hayford (1974) e Mackenzie e Seymour (1976) desenvolveram e aprofundaram a linha marxista na Geografia Feminista. Embora, originária da América do Norte, esta corrente alcançou um grande desenvolvimento dentro da Geografia Feminista Britânica (BOWLBY, 1989).

Dessa maneira, o atrelamento da Geografia Feminista à Geografia Marxista pode ser entendido como a busca de uma fundamentação teórica que possibilitasse o estudo das desigualdades sociais e das relações de gênero, unindo esfera social e esfera econômica. Evidentemente, as divisões que se instalam dentro da Geografia Feminista permitem outras formas de análise. Contudo, é essa corrente teórica que mais tem se refletido na Geografia Feminista internacional, demonstrando uma elevada difusão através de vários trabalhos, tanto no urbano como no rural e, criando e caracterizando uma Geografia de Gênero, comprometida com a mudança social, com a finalidade de eliminar as desigualdades de gênero. Assim, a união da esfera social a esfera econômica em uma mesma análise representou um significativo avanço para a Geografia Feminista como um todo. Neste contexto, o ponto em comum da Geografia Feminista com as abordagens críticas da Geografia está em "analisar e compreender porque a mulher permanece em uma posição subordinada" (WGSG, 1984, p. 20-21).

Já, o estabelecimento da Geografia Feminista, considerando que as implicações de gênero nos estudos geográficos possuem a mesma importância que as implicações de qualquer outro fator social ou econômico, que transforma a sociedade e o espaço (WGSG, 1984, p.21), demonstram a preocupação desta disciplina em determinar e analisar os papéis espaciais desempenhados pelas mulheres dentro das desigualdades sociais a que estão submetidas. No caso, o termo 'gênero' deve ser entendido como diferenciações socialmente criadas entre o feminino e o masculino, enquanto por 'sexo', embora essa terminologia não esteja sendo empregada no momento, este se refere às diferenças biológicas, associadas à reprodução entre homens e mulheres (WGSG, 1984, p. 21 e 25).

Deste modo, por Geografia Feminista deve-se entender aquela que

explicitamente leva em conta a estrutura de gênero socialmente criada da sociedade; e na qual, um compromisso tanto para aliviar a desigualdade de gênero em curto prazo quanto para a sua remoção, através de mudança social na direção da igualdade real, em um prazo mais longo, está expressa (WGSG, 1984, p.21).

Assim, após esta definição do 'Grupo de Estudo Geografia e Mulher', muitas outras foram desenvolvidas, algumas semelhantes e outras inovadoras. Nessa ordem, Ramon enfatiza,

Assim, a geografia feminista não é simplesmente uma geografia interessada em por em relevo as atividades das mulheres e suas implicações espaciais, senão que é aquela que 'de forma explícita considera a estrutura de gênero da sociedade e, ao mesmo tempo, contrai um compromisso com o objetivo de aliviar a curto prazo as desigualdades conseguintes e a sua erradicação através da mudança social a longo prazo'. A geografia feminista não tem 
porque ser cultivada somente por mulheres ou centrar-se exclusivamente nelas já que os enfoques feministas mais promissores são aqueles que englobam os papéis de gênero designados tanto a mulheres como a homens. Parece evidente que as implicações que o estudo de gênero pode ter na geografia são ao menos tão importantes como as da análise dos fatores sociais e/ou econômicos que conformam a sociedade e o espaço. (RAMON, 1985, p.136).

Ramon, desta maneira, reforça as afirmações do WGSG (1984) anteriormente destacadas. Já Bowlby (1986) acrescenta que

a geografia de gênero está interessada no estudo das desigualdades sócioespaciaisambientais, decorrentes dos diferentes papéis designados pela sociedade a homens e mulheres. As relações de gênero e as relações de poder entre homens e mulheres penetram em todos os pontos da vida social, pelo que ignorá-las empobrece a análise como a empobreceria ao ignorar as desigualdades de classe ou as centradas nas diferenças de raça" (BOWLBY, 1989, p.12).

Esta análise, incorpora as desigualdades de gênero, classe e raça e, ainda inclui o ambiente como uma área de estudo de gênero. Posteriormente, Ramon (1989) ressalta o papel da análise de gênero entorno da sua capacidade de mudança social, ou seja, de uma Geografia 'comprometida' com possibilidade de incorporar novos enfoques e conceitos junto a Geografia Humana e Geografia Social. Para tanto, centraliza sua análise sobre a união da esfera social a esfera econômica, ou seja, sobre a conexão do 'mundo do trabalho com o mundo do lar' e, salienta o trabalho de Monk e Hanson (1989) na superação desta separação, já que este, propõe a união de ambas esferas $\mathrm{e}$, insiste no papel fundamental que o lar desempenha na manutenção do sistema social, principalmente na reprodução da força de trabalho.

Argumenta ainda, que

o trabalho feminino já não se reduz somente na atualidade ao trabalho 'doméstico', sendo que em grau crescente, interfere diretamente na produção de mercadorias e, em particular, na economia informal, a mais pujante agora, tanto nos países avançados como nos do Terceiro Mundo. Tudo isto, implica numa interconexão ainda mais forte entre as esferas da produção e da reprodução. Qualquer análise que não relacione ambas esferas ficará incompleta e é, neste sentido, que a geografia de gênero pode fazer contribuições significativas para a base de nossa disciplina e contribuir com sua análise integradora para cobrir esta lacuna (RAMON, 1989, p.10).

Nesta questão da esfera social e esfera econômica, Rossini afirma que,

Hoje as pesquisas abordam a questão [o tema Mulher] do ponto de vista das relações sociais de gênero, isto é, a integração homem/mulher. Ambos formam uma unidade e embora à mulher nos discursos coubesse, tradicionalmente o papel específico da reprodução da espécie (produção social dos seres humanos), hoje já é reconhecido que ela também participa das outras atividades ligadas à produção de bens, isto é, a produção propriamente dita (ROSSINI, 1987, p.167).

Sem dúvida, desigualdades de gênero e trabalho se constituem em um dos caminhos para se esclarecer às origens da subordinação da mulher.

Deste modo, a partir da década de oitenta, os estudos de gênero e trabalho e gênero e trabalho familiar passaram a serem desenvolvidos pela Geografia de Gênero.

\section{Geografia de Gênero e Meío Rural}

O estudo de Gênero no contexto geográfico tem possibilitado o enquadramento da mulher dentro da temática espacial através do seu papel ativo, de atriz social, nas atividades produtivas e reprodutivas, produzindo e reproduzindo o espaço. Esse papel dá-se conjuntamente com os outros membros da família. Assim, até pouco tempo atrás, a maior parte dos estudos geográficos desenvolvidos sobre áreas rurais ignoravam a perspectiva de gênero, ou seja, o estudo da experiência da mulher que vive no meio rural era marginalizado, conjuntamente com o papel de gênero na organização da vida rural.

Deste modo, a partir da década de oitenta, vários estudos passaram a analisar o papel da mulher nas áreas rurais, nas atividades produtivas e reprodutivas, verificando os papéis de gênero atribuídos pela família, a divisão de trabalho por gênero e idade e as relações de poder dentro da unidade doméstica. Portanto, a 'invisibilidade' do trabalho desempenhado 
pela mulher tanto no setor produtivo como reprodutivo passou a ser destacada, bem como o seu 'sobretrabalho' e a diminuição do seu tempo de repouso. Essa invisibilidade é traduzida pelo 'trabalho doméstico' e pela ajuda familiar ${ }^{1}$, sendo que esta última traz em si mesma, o caráter não mercantil do trabalho, pois uma ajuda não implica em uma compensação monetária e, envolve uma relação de dependência. Ou seja, estes trabalhos dentro do contexto da valorização social, não apresentam valor em si, dependendo essa da instituição social onde se realiza no caso, do valor atribuído pela família, sendo desvalorizados socialmente, fato que se dá com a maioria do trabalho feminino realizado na esfera da reprodução e produção.

Dessa maneira, o sobretrabalho, a diminuição do tempo de repouso, bem como, a tentativa de quantificação do tempo dedicado às atividades produtivas e reprodutivas e também a especificação das tarefas atribuídas por gênero e idade são possíveis pela ampliação do conceito de trabalho que incorporou todas as atividades que objetivam a produção de bens e serviços desenvolvidas na esfera pública ou privada. Isso possibilitou a amarração da questão do trabalho feminino às relações de trabalho e à família. Ou seja, atualmente, a questão do trabalho feminino passa pelas relações de trabalho e família.

Desta forma, os estudos envolvendo a mulher e a criança no meio rural avançaram para as estratégias de sobrevivência familiar, isto é, para as atividades desenvolvidas por todos os membros da família fora e dentro da casa na manutenção de sua sobrevivência diária.

\section{Geografia de Gênero e Trabalho Familiar}

A Geografia de Gênero tem possibilitado o desenvolvimento de estudos centrados na ótica, que parte do trabalho para a produção e reprodução do espaço, entendendo as mulheres como atrizes sociais, que através de seus papéis ativos produzem e reproduzem o espaço. Porém, a análise não se centra somente na mulher, pois a mesma é responsável pela produção e reprodução dos homens, que reunidos em família conjuntamente com ela, produzem e reproduzem o espaço da sociedade (ROSSINI, 1988a).

Portanto, o estudo da problemática do trabalho feminino envolve hoje, necessariamente, as relações de trabalho e a família. "Neste caso, a unidade de estudo não é mais o indivíduo isolado, mas as peripécias que os indivíduos, a partir de suas relações mais próximas com os membros de sua família, realizam, para garantir a sobrevivência do grupo" (BARROSO, 1982, p.16).

A focalização do estudo na família e, não mais na mulher isoladamente, possibilita a visualização, ou melhor, a identificação do papel ativo desenvolvido pela mulher na atividade produtiva e reprodutiva.

Neste sentido, faz-se necessário entender o significado de família, que Durhan considera

como instituição, no sentido de Malinowski, isto é, como referente a um grupo social concreto, que existe como tal na representação de seus membros, o qual é organizado em função da reprodução (biológica e social) pela manipulação, de um lado, dos princípios formais da aliança, da descendência e da consanguinidade e, de outro, das práticas substantivas da divisão social do trabalho (DURHAN, 1983, p. 26).

Do mesmo modo, Bruschini e Madeira deixam claro que:

para entender e explicar a discriminação contra o sexo feminino era preciso deslocar o foco de análise para a posição da mulher dentro da unidade familiar. Ou seja, a participação dos indivíduos do sexo feminino na produção social não se define apenas pelas condições do mercado, pela estrutura de emprego ou, mais genericamente, pelo número de desenvolvimento da sociedade, mas também por sua posição dentro da família e pela classe social à qual pertence o grupo doméstico. Filha, esposa ou mãe, a cada uma dessas etapas do ciclo vital corresponderão determinadas necessidades e possibilidades de trabalho, que, dadas as oportunidades oferecidas pelo mercado, definirão a situação da mulher em relação às atividades produtivas. (BRUSCHINI e MADEIRA 1983, p.149).

Dessa forma, as análises dos estudos passaram a se concentrar nas estratégias de sobrevivência familiar, fato que levou à necessidade do conhecimento da atividade econômica conjunta da família.

Assim, no meio rural, a inserção da mulher e da criança, na atividade produtiva, se dá pelas dificuldades econômicas por que passam suas famílias, sendo necessária sua incorporação ao trabalho para a sobrevivência familiar. Nessa ordem, o trabalho fora do lar leva a mulher a um 'sobretrabalho' significativo, representado não só pela atividade produtiva, mas pelas atividades não produtivas, no caso, o trabalho cotidiano familiar. Neste, se enquadram tarefas diárias 
como o preparo do alimento, limpeza da casa, o cuidado com as crianças e os idosos, lavagem de roupas. Como uma das consequências deste processo tem-se a diminuição do tempo de repouso da mulher, enquanto o do homem continua o mesmo, fato que reflete em uma das muitas discriminações sofrida por esta nas relações familiares (ROSSINI, 1988b).

Já no caso das crianças, sua introdução prematura no mercado de trabalho impede a sua escolarização completa e permite sua exploração na atividade rural. Deste modo, muitas crianças, filhos de trabalhadores rurais são obrigados a deixar a escola para cuidar dos irmãos menores (ROSSINI, 1988b).

Do mesmo modo, Oliveira (1978) ao tratar da individualização da força de trabalho feminina em Pederneiras (SP), ressalta na época da safra de cana, a presença de crianças menores de quatorze anos trabalhando na divisão de um eito com um trabalhador adulto, o que demonstra o alto grau de exploração que sofrem os menores.

Portanto,

a mulher participa da produção e da reprodução da força de trabalho para o capital. E consequentemente, ela é responsável, juntamente com os outros membros da família, acrescido dos investimentos feitos pelos detentores do capital, pela produção e reprodução do espaço (ROSSINI, 1988b, p.588).

Neste contexto, a sobrevivência da família não se dá apenas através do dinheiro somante, mas do que as pessoas, membros da família fazem fora da casa, na propriedade para ajudar na manutenção da família como cultivar e/ou colher algum produto, cuidar de animais de pequeno porte e cuidados com a horta.

A respeito de sobrevivência familiar, Bruschini e Madeira destacam que:

(...) Cada vez mais tem sido enfatizado o fato de que, diversamente do que até pouco tempo era consenso, o emprego remunerado está longe de ser o único determinante do nível de vida e do bem-estar da população. A orientação é cada vez mais no sentido de mostrar que existe todo um conjunto de atividades, de natureza ainda pouco conhecida, mas que sem dúvida interferem na qualidade, na manutenção e na reprodução da força de trabalho. Atualmente descriminam-se cinco tipos de recursos aos quais a unidade doméstica ou seus membros, individualmente, podem ter acesso com o objetivo de satisfazer suas necessidades. O primeiro e mais importante é o ingresso monetário dos membros que trabalham com remuneração. Os outros recursos são não-monetários e, combinados com o salário, contribuem para a melhoria do padrão de vida das famílias. Entre eles estão os serviços públicos e sociais (por exemplo, a Previdência Social) cuja qualidade varia consideravelmente segundo o nível de desenvolvimento de cada região; os serviços sociais que não são administrados pelo Estado, mas por outras organizações específicas como a Igreja, os sindicatos etc. Além desses recursos, outros dois, também não-monetários, são vitais para a maioria das famílias: a produção doméstica de bens e serviços e o uso de relações sociais informais com parentes, vizinhos e amigos, com os quais se estabelece uma rede de ajuda mútua (BRUSCHINI e MADEIRA, 1986, p.152).

Dessa maneira, toda uma estratégia de sobrevivência familiar é desenvolvida pela família na manutenção do grupo e, onde, a mulher desempenha um importante papel como atriz social, produzindo e reproduzindo o espaço.

Assim, em relação à condição da mulher, verificase que em toda formação social existe uma produção social de bens (produção) e uma produção social de seres humanos (reprodução), que são distintas, porém relacionadas uma a outra. Deste modo, produção e reprodução são indissociáveis. Com o advento do sistema capitalista tem-se a definição da subordinação da reprodução à produção. Dessa maneira, no decurso da história, constata-se que homens e mulheres participam de modo desigual da produção e reprodução, sendo que esta participação foi reforçada no sistema capitalista (ROSSINI, 1988a).

Neste sentido, a efetivação do capitalismo proporciona às mulheres diferentes situações, ou seja, mulheres ricas possuem condições diferentes das mulheres da classe operária. Ou seja, o capitalismo aumentou à exploração de sua força de trabalho, como também das crianças (ROSSINI, 1988a).

Portanto, é o trabalho familiar, desenvolvido por todos os membros da família, que possibilita a verificação do papel de atriz social da mulher nas atividades produtivas e reprodutivas produzindo e reproduzindo o espaço.

\section{Conclusões}


Observou-se que a origem da Geografia de Gênero está relacionada à Geografia Neopositivista, a Geografia Humanística e a Geografia Marxista.

Atestou-se, que a junção da Geografia Feminista à Geografia Marxista visava o desenvolvimento de uma fundamentação teórica que possibilitasse o estudo das desigualdades sociais e das relações de gênero ligando esfera social e esfera econômica.

Concluiu-se, que a Geografia de Gênero pode ser entendida como a parte da Geografia, que estuda as desigualdades sócioespaciais-ambientais decorrentes dos diferentes papéis designados pela sociedade a homens e mulheres.

Constatou-se, que o estudo de gênero na Geografia possibilitou o enquadramento da mulher na temática espacial através de seu papel ativo de atriz social nas atividades produtivas e reprodutivas, produzindo e reproduzindo o espaço conjuntamente com outros membros da família.

Assim, verificou-se que, atualmente, a questão do trabalho feminino passa pelas relações de trabalho e família. No meio rural, estes estudos avançaram para as estratégias de sobrevivência familiar, ou seja, para as atividades desenvolvidas por todos os membros da família, fora e dentro da casa, na manutenção de sua sobrevivência.

1 O trabalho desenvolvido pelas mulheres nas atividades agrícolas é considerado na maior parte das vezes como " ajuda "e não como trabalho, a não ser quando as mulheres desenvolvem trabalhos agrícolas que são considerados masculinos.

\section{Referências}

BARROSO, Carmen Lúcia de Melo. Mulher, Sociedade e Estado no Brasil. São Paulo: Brasiliense, 1982.

BISTUER, Josepa. Medi Ambienti i Equitat: la Perspectiva del Gènere. Documents d'Anàlisi Geogràfica, vol. 22, p. 117 - 130, 1993.

BOWLBY, Sophie. The Feminist Challenge to Social Geography. London: Text, 1986.

Geografía Feminista en Gran-Bretanã: una Década de Cambio. Documents d'Anàlisi Geogràfica, vol. 14, p. 15 - 29, 1989.

BOWLBY, Sophie (et al).The Geography of Gender. In: PEET, Richard. THRIFT, Nigel. New models in
Geography, London: Unwin Hyman, 1986. p.157-175.

BRUSCHINI, Cristina; MADEIRA, Felícia Reicher. A família, a estrutura social e as formas de participação na produção social. CERU, vol. 18, p. 147 - 186, 1983.

BUCHANAN, Keith. The Map of Love. Sydney: Pergamon, 1970.

BURNETT. Pat. Social Change, the Status of Women and Models of City Form and Development. Antipode, vol. 5, p. 57 - 62, 1973.

BURTON, Linda. The Country and the City: the Effects of Women's Changeng Rolesand Attitudes on Their View of the Environment in Contemporary Fection. In: BURNETT, Pat. Women in Society: a New Perspective. London: Croom Helm, 1976. p. 83 95.

BUTTIMER, Anne. Beyond Sexist Rhetoric: Horizons for Human Becoming. In: BURNETT, Pat. Women in Society: a New Perspective. London: Croom Helm, 1976, p. 59-70.

CALIÓ, Sonia Alves. Relações de Gênero na Cidade. 1991. Tese (Doutorado em Geografia Humana) Programa de Pós-Graduação em Geografia Humana, FFLCH/USP, São Paulo - SP.

DANKELMAN Irene; DAVIDSON, Joan. Women and Environment in the Third World. London: Earthscan, 1988.

DURHAN, Eunice Ribeiro. A família e a mulher. CERU, vol. 18, p. 7 - 47, 1983.

FORTUYN, Maas Droogleever. Vrouwenemancipatie en de Werkwize in Het Planologisch Onderzoek. Ruimte Beperkend of Bevrijdend? Den Haag: Provincie Zuid-Holland, 1984.

HAYFORD, Alison. The Geography of Women: An Historical Introduction. Antipode, vol. 6, $\mathrm{n}^{\mathrm{o}} 2$, p. 1 19, 1974.

KARSTEN, Lia; MEERTENS, Donny. La Geografia del Gènero: sobre Visibilidad, Identidad y Relaciones de Poder. Documents d'Anàlisi Geogràfica, vol 1920, p. 181-193, 1991/1992.

LARIMORE, Anne Evans. Humanizing the Writing in Cultural Geography Text Books. Journal of 
Geography, vol. 77, p. 183 - 185, 1978.

LIBBEE, Kristin Sheridan. ; LIBBEE, Michel. Geographic Education and the Women's Movement. Journal of Geography, vol. 77, p. 176 - 180, 1978.

MACKENZIE, Suzanne; SEYMOUR, Linda. The Role of the Family Under Contemporay Urbanism. Paper Presented at Annual Meeting of the Canadian Association of Geography. 1976.

McDOWELL, Linda. Beyond Patriarchy: A Class-Base Explanation of Women Subordination. Antipode, vol. 18, no 3, p. 311-321, 1986.

MIES, Maria. Perfiles de una Sociedad Ecofeminista. Intento de un Proyecto.México: Cdhal, 1990.

MONK, Janice; HANSON, Susan. Temas de Geografia Feminista Contemporánea. Documents d'Anàlisi Geogràfica, Barcelona, vol. 14, p. 31 - 50, 1989.

MONK, Janice; RAMON, Maria Dolores. Gárcia. Geografia Feminista: uma Perspectiva Internacional. Documents d'Anàlisi Geogràfica, vol. 10, p. 147 $157,1987$.

OLIVEIRA, Maria Coleta de. A Individualização da Força de Trabalho e o Trabalho Feminino em Pederneiras - SP. In: $\mathbf{1}^{\mathbf{0}}$ Encontro Nacional de Estudos Populacionais, 1978, Campos do Jordão. Anais de Resumo. Campo do Jordão: ABEP, 1978. p. 383-403.

PALM, Risa; PRED, Allan. A Time-Geographic Perspective on Problems of Inequality for Women. Working Paper, Berkeley, 1974.

PALM, Risa; PRED, Allan. Una Perspectiva Geográfico - Temporal de Los Problemas de Desigualdad de Las Muyeres. In: RAMON, Maria Dolores Gárcia. Teoria y Método en la Geografía Humana Anglosayona. Barcelona: Ariel, 1985, p.107131.

RAMON, Maria Dolores Gárcia. El Análisis de Género y la Geografía: Reflexiones en torno a un Livro Reciente. Documents d'Anàlisi Geogràfica, Barcelona, vol. 6, p. 133 - 143, 1985.

RAMON, Maria Dolores Gárcia. Género, Espacio y Entorno: Hacia una Renovación Conceptual de la Geografía? Una Introducción. Documents d'Anàlisi
Geogràfica, vol. 14, p. 7 - 13, 1989.

ROSSINI, Rosa Ester. Mulher e Trabalho: Imposição ou Libertação o Trabalho na Agricultura. In: 8o Encontro Nacional de Geografia Agrária, 1987, Barra do Coqueiro. Anais de Resumo. Barra do Coqueiro:AGB, 1987. p.167-168.

Geografia e Gênero: A Mulher na Lavoura Canavieira Paulista. 1988a. Tese (LivreDocência em Geografia Humana) - FFLCH/USP, São Paulo, SP.

Mulher: Residência no Urbano, Sobrevivência no Rural (o exemplo da Lavoura Canavieira). In: 6o Encontro Nacional de Estudos Populacionais, Olinda. Anais de Resumo. Olinda: ABEP, 1988b. p. 16-20.

SEAGER, Joni; OLSON, Anne. Women in the World: an International Atlas. New York: Pluto Press, 1986.

SHIVA, Vandana. Abrazar la vida: Mujer, Ecología y Supervivencia. Montevideo: Inst. del Tercero Mundo, 1991.

SONTHEIMER, Sally. Women and the Environment. New York: Monthly Review Press, 1991.

WOMEN AND GEOGRAPHY STUDY GROUP OF THE IBG. Geography and Gender: an Introduction to Feminist Geography. London: Hutchinson, 1984.

Recebido em 01 de outubro de 2010. Aceito em 20 de fevereiro de 2011. 